\title{
Alemtuzumab in the up-front setting
}

\author{
Matthew Kaufman \\ Kanti R Rai \\ Long Island Jewish Medical Center, \\ New Hyde Park, NY, USA
}

\begin{abstract}
Alemtuzumab is a humanized chimeric monoclonal antibody targeting CD52. Although this agent already has an important role in the treatment of chronic lymphocytic leukemia (CLL), many of its uses are still being defined. Early trials showed alemtuzumab's value in refractory disease and helped to define its excellent activity in the bone marrow, spleen and 17p deleted patients. The CAM307 trial has demonstrated alemtuzumab's efficacy as monotherapy in the front-line setting, and ultimately led to its FDA approval as frontline therapy. Especially promising is the trend toward improved response in patients with high risk cytogenic abnormalities (17p del, 11q del, trisomy 12). The various consolidation trials have also provided promising results of achieving eradication of minimal residual disease (MRD). Although the ultimate benefit of achieving MRD negativity remains under investigation, alemtuzumab's potent activity on the bone marrow will likely make it an important part of combination therapy.

Keywords: alemtuzumab, chronic lymphocytic leukemia, consolidation, minimal residual disease, $17 \mathrm{p}$ deletion, $11 \mathrm{q}$ deletion
\end{abstract}

\section{Introduction}

Alemtuzumab is a humanized chimeric monoclonal antibody targeting CD52. Although this agent already has an important role in the treatment of chronic lymphocytic leukemia (CLL), many of its uses are still being defined. Most experience using alemtuzumab has been in the relapsed and refractory setting. Its initial FDA approval in CLL was based on a pivotal trial of 93 fludarabine-refractory patients (Keating et al 2002). Alemtuzumab's particularly good activity in high risk patients at clearing peripheral blood, bone marrow and spleen of CLL cells have led to its consideration in the firstline setting. The impressive results of a recent study, the CAM307 trial, have led to alemtuzumab's approval for up-front use in CLL. Despite its approval in both upfront and relapsed settings, alemtuzumab's role in CLL treatment continues to evolve.

\section{The case for alemtuzumab in the up-front setting}

Ample evidence of alemtuzumab's efficacy in difficult patient populations and in specific disease scenarios have ultimately led to its examination in the front-line setting. In 1997, Osterborg et al (1997) published the results of a European, multi-center trial in 1997 using single-agent alemtuzumab in 29 CLL patients who had relapsed after first-line treatment or who had refractory disease. The overall response rate was $41 \%$ and complete response was $4 \%$. Its efficacy at clearing CLL cells from the peripheral blood ( $97 \%$ of patients) and from the bone marrow (36\% of patients) was particularly notable. In addition, splenomegaly completely resolved in $32 \%$ of patients. On the other hand, lymph nodes were reduced to normal in only $2 \%$. Rai et al (2002a) published a study in which 24 fludarabine-refractory patients received single-agent alemtuzumab and obtained a response-rate of 33\% (there were no complete responses). Also in 2002, Keating et al (2002) published data from the CAM211 trial in which 93 fludarabine-refractory patients received alemtuzumab and achieved a $33 \%$ overall response rate. 
Table I Alemtuzumab monotherapy trial in front-line setting

\begin{tabular}{|c|c|c|c|c|c|}
\hline Study & Patients & Regimen & Response rate & Complete response & $\begin{array}{l}\text { Median progression- } \\
\text { free survival }\end{array}$ \\
\hline $\begin{array}{l}\text { Osterberg et al (1996) } \\
\text { single arm pilot study }\end{array}$ & $n=9$ & $\begin{array}{l}\text { Alemtuzumab } 30 \mathrm{mg} \\
\text { TIW for I } 8 \text { weeks (4 } \\
\text { patients received SQ; } \\
5 \text { patients received IV) }\end{array}$ & $89 \%(n=8)$ & $33 \%(n=3)$ & \\
\hline $\begin{array}{l}\text { Lundin et al (2002) } \\
\text { phase II single arm } \\
\text { study }\end{array}$ & $n=4 I$ & $\begin{array}{l}\text { Alemtuzumab } 30 \mathrm{mg} \\
\text { TIW for } 18 \text { weeks SQ }\end{array}$ & $87 \%(n=38)$ & $19 \%(n=7)$ & \\
\hline Hillmen et al (2006) & $\begin{array}{l}n=297 \text { for entire } \\
\text { trial; } n=149 \text { for } \\
\text { alemtuzumab arm }\end{array}$ & $\begin{array}{l}\text { Alemtuzumab } 30 \mathrm{mg} \\
\text { TIW for } 12 \text { weeks }\end{array}$ & $\begin{array}{l}\text { Alemtuzumab arm } \\
83 \%(n=124)\end{array}$ & $\begin{array}{l}\text { Alemtuzumab arm } \\
24 \%(n=36)\end{array}$ & $\begin{array}{l}\text { Alemtuzumab } \\
\text { arm }=21.7 \text { months }\end{array}$ \\
\hline $\begin{array}{l}\text { CAM307 Phase III } \\
\text { study of alemtuzumab } \\
\text { vs chlorambucil }\end{array}$ & $\begin{array}{l}\mathrm{n}=148 \text { chlorambucil } \\
\text { arm }\end{array}$ & $\begin{array}{l}\text { Chlorambucil } \\
40 \mathrm{mg} / \mathrm{m}^{2} \text { PO q28 days } \\
\text { for } \max 12 \text { cycles }\end{array}$ & $\begin{array}{l}\text { Chlorambucil arm } \\
55 \%(\mathrm{n}=82)\end{array}$ & $\begin{array}{l}\text { Chlorambucil arm } \\
2 \%(n=3)\end{array}$ & $\begin{array}{l}\text { Chlorambucil } \\
\text { arm }=12.5 \text { months }\end{array}$ \\
\hline
\end{tabular}

Further evidence to help define alemtuzumab's role in high risk patients was shown in a study by Stilgenbauer et al (2002) in 2002. A response rate of 54\% was achieved in fludarabine-refractory patients with the unfavorable mutation $17 \mathrm{p}$ deletions or $\mathrm{p} 53$ abnormalities. A subsequent trial performed by Lozanski et al (2004) found a 31\% response in patients with this high-risk profile.

Alemtuzumab's use in combination with other agents also showed impressive results in refractory disease. The combination of alemtuzumab and fludarabine was examined in trials published by Kennedy et al (2002) $(\mathrm{n}=6)$ and Elter et al 2005) $(\mathrm{n}=36)$. Both studies found an overall response rate of $83 \%$. Faderl et al (2003) used alemtuzumab in combination with rituximab in this population and achieved a response rate of $63 \%$. This history of success in these profiles of high-risk populations, particularly with p53 deletions, extensive marrow disease with high peripheral lymphocyte counts, and without bulky lymph nodes, led investigators to examine roles for alemtuzumab in the up-front setting.

\section{Alemtuzumab monotherapy in the first-line setting}

Use of alemtuzumab as monotherapy in CLL in the first-line setting was first reported by Osterborg et al (1996) in a pilot study of 9 patients (Table 1). Five received intravenous and 4 received subcutaneous alemtuzumab at a dose of $30 \mathrm{mg} 3$ times/week for a maximum of 18 weeks. Five patients achieved a partial remission and 3 achieved a complete remission. Duration of response ranged from 8 to 24 months. A phase II study was published in 2002 (Lundin et al 2002). Single-agent alemtuzumab was administered subcutaneously thrice weekly for 18 weeks to 41 patients as first-line treatment. Thirty-eight patients responded to therapy, for an overall response rate of $87 \%$ ( 95\% CI, 76\%-98\%) - 19\% achieved a complete remission and $68 \%$ achieved a partial remission. $95 \%$ of patients cleared CLL cells in their peripheral blood at a median of 21 days of treatment, and $66 \%$ achieved CR or nodular PR in the bone marrow after the full course of 18 weeks of treatment. The treatment was generally well-tolerated with neutropenia (21\%) and cytomegalovirus (CMV) reactivation (10\%) being the most serious toxicities. There were transient injection-site skin reactions in $90 \%$ of patients.

\section{The CAM307 trial}

Results of an international prospective, randomized, controlled trial comparing alemtuzumab to chlorambucil as front-line therapy was reported at the American Society of Hematology annual meeting in 2006 (Hillmen et al 2006) and published in December 2007 (Hillmen et al 2007). A total of 297 patients were accrued, and were randomized to receive either alemtuzumab $(n=149) 30 \mathrm{mg}$ IV thrice weekly for up to 12 weeks or chlorambucil $(\mathrm{n}=147) 40 \mathrm{mg} / \mathrm{m}^{2}$ PO every 28 days for a maximum of 12 cycles. The primary endpoint was progression-free survival (PFS) and secondary endpoints were response rate, overall survival, and safety.

The alemtuzumab arm showed an overall response rate of $83 \%$ compared to a $55 \%$ response rate in the chlorambucil arm. Complete responses were seen in $24 \%$ and of the alemtuzumab arm and $2 \%$ of the chlorambucil arm. MRD negativity was achieved in 11 of 36 complete responders in the alemtuzumab arm vs none in the chlorambucil arm. Time to alternative treatment was 23.3 months for the alemtuzumab arm vs 14.7 months for the chlorambucil arm $(p=0.0001)$. 
Table 2 Alemtuzumab consolidation trials

\begin{tabular}{|c|c|c|c|c|c|}
\hline Study & Patients & Regimen & Response rate & MRD negativity & $\begin{array}{l}\text { Median progression- } \\
\text { free survival/ } \\
\text { survival }\end{array}$ \\
\hline $\begin{array}{l}\text { O'Brien et al (2003) } \\
\text { Alemtuzumab con- } \\
\text { solidation with } 10 \mathrm{mg} \\
\text { vs } 30 \mathrm{mg} \text { doses }\end{array}$ & $n=4 I$ & $\begin{array}{l}\text { Alemtuzumab given } \\
\text { after fludarabine induc- } \\
\text { tion in the following } \\
\text { doses: } 10 \mathrm{mg} \text { IVTIW } \\
\text { for } 4 \text { weeks }(n=24) \text {; } \\
\text { or } 30 \mathrm{mg} \text { IV TIW for } \\
4 \text { weeks }(n=34)\end{array}$ & $\begin{array}{l}\text { Improved response after } \\
\text { induction all patients }=46 \% \\
(\mathrm{n}=19): 30 \mathrm{mg} \text { arm }=56 \% \\
10 \mathrm{mg} \text { arm }=39 \%\end{array}$ & $\begin{array}{l}38 \% \text { (I I of the } 29 \\
\text { patients tested for } \\
\text { MRD) }\end{array}$ & $\begin{array}{l}\text { Not reached at median } \\
\text { follow of } 18 \text { months }\end{array}$ \\
\hline $\begin{array}{l}\text { Wendtner et al (2003) } \\
\text { phase III trial of alemtu- } \\
\text { zumab vs observation } \\
\text { following fludarbine- } \\
\text { based therapy }\end{array}$ & $n=21$ & $\begin{array}{l}\text { Alemtuzumab } 30 \mathrm{mg} \\
\text { SQTIW consolidation vs } \\
\text { observation following a } \\
\text { response to fludarabine- } \\
\text { based therapy }\end{array}$ & $\begin{array}{l}\text { (I8\%) } 2 \text { of II on alemtu- } \\
\text { zumab arm had improved } \\
\text { response over induction }\end{array}$ & $\begin{array}{l}83 \% \text { ( } 5 \text { of } 6 \text { patients } \\
\text { tested for MRD in } \\
\text { peripheral blood) }\end{array}$ & $\begin{array}{l}\text { Alemtuzumab arm: not } \\
\text { reached at median fol- } \\
\text { low up of } 21.4 \text { months. } \\
\text { Observation arm: } \\
24.7 \text { months }\end{array}$ \\
\hline $\begin{array}{l}\text { Moreton et al (2005) } \\
\text { Treatment of fludarabine- } \\
\text { refractory patients to } \\
\text { best possible remission }\end{array}$ & $\mathrm{n}=91$ & $\begin{array}{l}\text { Alemtuzumab } 30 \mathrm{mg} \\
\text { TIW (SQ or IV) until } \\
\text { maximum response } \\
\text { (median } 9 \text { weeks) }\end{array}$ & $\begin{array}{l}53 \%(n=49) \text { overall } \\
\text { response rate. } 36 \% \\
(n=32) \text { had CRs }\end{array}$ & $20 \%(n=18)$ & $\begin{array}{l}\text { Overall survival for } \\
\text { MRD- patients not } \\
\text { reached. Overall } \\
\text { survival for MRD+ } \\
\text { patients with CRs had } \\
\text { a median survival of } \\
41 \text { months. }\end{array}$ \\
\hline $\begin{array}{l}\text { CALGB (2003) Alem- } \\
\text { tuzumab following } \\
\text { fludarabine in previously } \\
\text { untreated patients }\end{array}$ & $n=24$ & $\begin{array}{l}\text { Alemtuzumab } 30 \mathrm{mg} \\
\mathrm{SC} \text { for } 6 \text { weeks follow- } \\
\text { ing fludarabine }\end{array}$ & $\begin{array}{l}66 \% \text { overall response } \\
\text { ( } 12 \text { of I8 patients who } \\
\text { received alemtuzumab); } \\
22 \% \text { CR; } 44 \% \text { PR }\end{array}$ & & \\
\hline $\begin{array}{l}\text { Montillo et al (2004) } \\
\text { phase II study of alemtu- } \\
\text { zumab following clinical } \\
\text { response to fludarabine }\end{array}$ & $\mathrm{n}=34$ & $\begin{array}{l}\text { Alemtuzumab } 10 \mathrm{mg} \\
\mathrm{SC} \text { for } 6 \text { weeks following } \\
\text { response to fludarabine }\end{array}$ & $\begin{array}{l}53 \% \text { ( } 18 \text { of } 34) \text { patients } \\
\text { had improved response } \\
\text { over induction }\end{array}$ & $56 \%(n=19)$ & \\
\hline
\end{tabular}

Abbreviations: $C R$, complete response; MRD, minimal residual disease; $P R$, partial response.

Especially notable was that these benefits were particularly evident in patients with high-risk cytogenetic abnormalities. Of the 282 patients who had cytogenetic analysis, 231 patients (82\%) revealed abnormalities, including 19\% with $11 \mathrm{q}$ deletions, $7 \%$ with $17 \mathrm{p}$ deletions and $14 \%$ with trisomy 12 (Robak et al 2006). Patients with $17 \mathrm{p}$ deletions who were treated with alemtuzumab had a PFS of 10.7 months compared to 2.2 months for patients who received chlorambucil. Overall response rates for these two groups were $64 \%$ and $20 \%$, respectively. Patients with $11 \mathrm{q}$ deletions had response rates of $87 \%$ and $29 \%$ in the alemtuzumab and chlorambucil arms, respectively. PFS was 8.5 months in both arms. Similarly, patients with trisomy 12 had a PFS of 18.3 months vs 12.9 on the alemtuzumab and chlorambucil arms, respectively. These two groups had similar response rates of $83 \%$ in the alemtuzumab arm and $80 \%$ in the chlorambucil arm. Of particular note, however, is that although these benefits for patients with high risk cytogenetics were statistically significant in terms of response, this did not extend to PFS. Although there was a trend of increased PFS in the 17p group treated with alemtuzumab, it did reach statistical significance.

In terms of toxicities, the incidence of grade 3 and 4 neutropenia occurred in $45 \%$ of the alemtuzumab arm vs $26 \%$ of the chlorambucil arm. Infectious complications were reported in $76 \%$ of patients on the alemtuzumab arm compared to $50 \%$ on the chlorambucil arm. CMV viremia occurred in 52\% of patients on the alemtuzumab arm and $16 \%$ had symptomatic CMV infections. Only 7.5\% of patients on the chlorambucil had evidence of CMV viremia by PCR, none of whom were symptomatic.

Although this trial adds important data in terms of the use and activity of alemtuzumab as single-agent in the front line, the results must be cautiously interpreted due to its relatively short median follow-up of only 24.6 months, and the fact that $84 \%$ of patients in each arm remain alive. Nevertheless, the trial adds particularly useful data in terms of approach to $17 \mathrm{p}$ deleted patients, and may ultimately contribute to the creation of a new standard of care for these patients. 


\section{Alemtuzumab consolidation}

Although alemtuzumab has been shown to be less effective treating bulky lymph nodes, multiple studies have demonstrated its utility in clearing the blood and bone marrow of disease (Dyer et al 1997; O'Brien et al 2003). Based on these observations, alemtuzumab has been used in several trials as consolidation therapy to eradicate minimal residual disease (MRD) in the bone marrow after initial therapy with other agents to debulk peripheral lymph nodes (Table 2).

In 1997 Dyer et al (1997) published a small study of 6 CLL patients who were treated with fludarabine, had persistent disease in the bone marrow, and then were treated with alemtuzumab. Five of the 6 patients achieved a hematologic and histological complete remission following alemtuzumab. O'Brien et al (2003) further examined the concept of eradication of MRD in a series of 41 patients. Forty-six per cent of the patients overall, and $56 \%$ of those patients that received the $30 \mathrm{mg}$ dose $(\mathrm{n}=17)$ had improvement in their disease-response after the alemtuzumab treatment. Eleven (38\%) of the 29 patients whose bone marrow was tested by two-color flow cytometry achieved a flow-negative remission. At a median follow-up of 18 months, 6 patients remained disease-free (24-48 months after therapy) and median time to disease progression had not yet been reached at the time of their report or until 18 months median follow-up. Fifteen patients (37\%) were reported to have infectious complications, 9 of which were CMV reactivations.

At the annual meeting of the American Society of Clinical Oncology in 2005, Wendtner et al (2004) and the German CLL Study Group presented the results of a trial that randomized patients who responded to fludarabine/ cyclophosphamide or fludarabine alone to either alemtuzumab $30 \mathrm{mg}$ subcutaneous 3 times per week for 12 weeks or observation. The trial was ultimately stopped early due to severe infectious toxicities. Of the 21 evaluable patients, 11 were randomized to receive alemtuzumab. Patients in the alemtuzumab arm showed a significantly longer PFS compared to those in the observation arm (no progression at a median of 21.4 months follow up vs 24.7 months). Seven of the 11 patients on the alemtuzumab arm had infectious complications including one life-threatening case of pulmonary aspergillosis, 4 patients with CMV reactivation (2 with clinically evident CMV pneumonia), 1 tuberculosis and 1 herpes zoster infection.

Moreton et al (2005) published a larger study in 2005 using alemtuzumab in consolidation. Although these patients were previously treated, consolidation proved to be an attractive concept in the front-line setting as well. Ninety-one patients received alemtuzumab for a median of 9 weeks. Thirty-six per cent obtained a complete remission, including $20 \%(\mathrm{n}=18)$ who had obtained MRD negativity by flow cytometry. Of note, the patients who achieved MRD negativity had a significantly prolonged treatment-free survival compared with patients with MRD positivity but with a clinical complete response (CR) (median treatment-free survival not reached vs 20 months, respectively ( $p<0.0001)$. MRD negative patients had not reached median overall survival vs median overall survival of 60 months for those patients that obtained CR but not MRD negativity. This study helped to initiate discussion as to whether or not MRD negativity should be a new goal of treatment (Montserrat 2005). It remains unclear as to whether achievement of MRD-negativity itself results in a better outcome, or if the ability to clear the bone marrow simply represents a group of patients with more sensitive disease. The issue is still being debated.

The Cancer and Leukemia Group B (CALGB) conducted a study using alemtuzumab following fludarabine in the firstline (Rai et al 2002b, 2003). Fifty-six patients were enrolled and received 4 monthly cycles of single-agent fludarabine. Patients that achieved stable disease or better after 2 months of observation following fludarabine received alemtuzumab $30 \mathrm{mg}$ intravenously TIW for 6 weeks, intravenously. Another 24 patients underwent the same fludarabine regimen, but received alemtuzumab subcutaneously if a response was achieved. In the first group (designated to receive intravenous alemtuzumab), 36 of the 56 patients ultimately received alemtuzumab IV. Fifteen of those 36 improved to CRs (42\%) and 18 had PRs (50\%) for an overall improvement of response rate to $92 \%$. Of the 24 patients in the second (subcutaneous alemtuzumab) group, 18 patients qualified to get subcutaneous alemtuzumab. Of those 18 patients, 12 (66\%) improved their response, including 22\% who achieved CRs and 44\% who achieved PRs.

Mantillo et al also examined the achievement of MRD negativity following alemtuzumab consolidation in a phase II study of 34 patients (Montillo et al 2006). Patients who had a clinical response to fludarabine-based therapy in the front-line received alemtuzumab $10 \mathrm{mg}$ subcutaneously TIW for 6 weeks. Patients went on to have stem cell mobilization for transplant. Following treatment with the alemtuzumab, the CR rate improved from $35 \%$ after the fludarabine treatment to $79 \%$. Nineteen patients (56\%) achieved MRD negativity. There was CMV reactivation in 18 patients, all of whom were successfully treated with antiviral therapy. 
Twenty-four of these patients underwent successful stem cell collection and 18 underwent autologous bone marrow transplant.

\section{Infectious toxicities of alemtuzumab}

Alemtuzumab has well-known infectious complications. As described in the pivotal trials above, major infectious complications were observed in approximately half of the patients (Keating et al 2002; Rai et al 2002a). These infections included septicemia, opportunistic infections such as aspergillosis, Pneumocystis carinii, herpes simplex (re)activations, and cytomegalovirus. Generally, these infectious complications have been found to be more common in patients who are not responding to alemtuzumab thereapy (Rai et al 2002a; Montillo et al 2006). In one study, Rai et al found major infections in only 2 of 8 responders, compared with 8 of 16 nonresponders. A retrospective evaluation of 27 patients treated for lymphoid malignancies at Dana Farber/Brigham and Women's Hospital found that 56\% (15 of 27) experienced opportunistic infections (including CMV(44\%), progressive multifocal leukoencephalopathy, adenovirus, toxoplasmosis, and acanthamaebiasis). In addition, 30\% nonopportunistic infections were found in 22 patients (Martin et al 2006). These complications are particularly common when alemtuzumab is combined with purine analogs (Keating et al 2002).

Cytomegalovirus (CMV) infection is the most common complication. In the CAM307 trial, $52.4 \%$ of patients receiving alemtuzumab have asymptomatic positive CMV by PCR vs $7.5 \%$ of the patients who received chlorambucil. An additional $15.6 \%$ of patients on the alemtuzumab arm had symptomatic CMV involvement (Hillmen et al 2007).

Close monitoring of CMV copies by PCR during treatment with alemtuzumab allows for detection of asymptomatic reactivation. There should be high suspicion of CMV infection in any patient with unexplained fever, increase in LFTs or respiratory symptoms, even with no detectable CMV in the blood. Typically, if CMV is detected, or if there is a high suspicion on infection, alemtuzumab is temporarily held and antiviral therapy is initiated. Some debate does exist as to what point alemtuzumab should be held and restarted. Published guidelines by O'Brien et al (2006) suggest that alemtuzumab be held only in the setting of severe infection or persistent symptoms.

Once signs and symptoms of infection have resolved, the therapy should be restarted. Both symptomatic and asymptomatic $\mathrm{CMV}$ in these patients usually responds to gancyclovir. Prophylaxis for prevention of varicella zoster and herpes simplex reactivation, as well as for pneumocystis carinii pneumonia, should also be given throughout treatment. These prophylactic antibiotics and CMV monitoring should be continued following alemtuzumab for approximately 6-8 months, and at least until recovery of CD4+ T-cells.

\section{Conclusion}

Alemtuzumab's role continues to expand. Early trials showed alemtuzumab's value in refractory disease and helped to define its excellent activity in the bone marrow, spleen and $17 \mathrm{p}$ deleted patients. With this data, additional trials were developed in an attempt to further expand its role. The CAM307 trial has demonstrated alemtuzumab's efficacy as monotherapy in the front-line setting. Especially promising is the trend toward improved response in patients with high risk cytogenic abnormalities (particularly $17 \mathrm{p}$ del). This trend requires further investigation but notwithstanding, alemtuzumab is a reasonable first-line choice for this population. The various consolidation trials have also provided promising results of achieving eradication of minimal residual disease (MRD). Although the ultimate benefit of achieving MRD negativity remains under investigation, alemtuzumab's potent activity on the bone marrow will likely make it an important part of combination therapy.

\section{References}

Dyer MJ, Kelsey SM, Mackay HJ, et al. 1997. In vivo purging of residual disease in CLL with Campath-1H. Br J Haematol, 97:669-72.

Elter T, Borchmann P, Schultz H, et al. 2005. Fludarabine in combination with alemtuzumab is effective and feasible in patients with relapsed or refractory B-cell chronic lymphocytic leukemia results of phase II trial. J Clin Oncol, 23:7024-31.

Faderl S, Thomas DA, O’Brien S, et al. 2003. Experience with alemtuzumab plus rituximab in patients with relapsed and refractory lymphoid malignancies. Blood, 101:3413-5.

Hillmen P, Skotnicki A, Robak T, et al. 2006. Preliminary phase III efficacy and safety of alemtuzumab vs chlorambucil as front-line therapy for patients with progressive B-cell chronic lymphocytic leukemia (BCLL) [abstract]. J Clinc Oncol, 24(Suppl):339s. Abstract 6511.

Hillmen P, Skotnicki A, Robak T, et al. 2007. Alemtuzumab compared with chlorambucil as first-line therapy for chronic lymphocytic leukemia. J Clin Oncol, 25:5616-23.

Keating MJ, Flinn I, Jain V, et al. 2002. Therapeutic role of alemtuzumab (Campath 1-H) in patients who have failed fludarabine: results of a large international study. Blood, 99:3554-61.

Kennedy B, Rawstron A, Carter C, et al. 2002. Campath-1H and fludarabine in combination are highly active in refractory chronic lymphocytic leukemia. Blood, 99:2245-47.

Lozanski G, Heerema NA, Flinn IW, et al. 2004. Alemtuzumab is an effective therapy for chronic lymphocytic leukemia with p53 mutations and deletions. Blood, 103:3278-81.

Lundin J, Kimby E, Bjorkholm M, et al. 2002. Phase II trial of subcutaneous anti-CD52 monoclonal antibody alemtuzumab (Campath 1-H) as firstline treatment for patients with B-cell chronic lymphocytic leukemia (B-CLL). Blood, 100:768-73. 
Martin SI, Marty FM, Fiumara K, et al. 2006. Infectious complications associated with alemtuzumab use for lymphoproliferative disorders. Clin Infect Dis, 43:16-24.

Montillo M, Tedeschi A, et al. 2006. Alemtuzumab as consolidation after a response to fludarabine is effective in purging residual disease in patients with chronic lymphocytic leukemia. J Clin Oncol, 24:2337-42.

Montserrat E. 2005. Treatment of chronic lymphocytic leukemia: achieving minimal residual disease negative status as a goal. J Clin Oncol, 23:2884-5.

Moreton P, Kennedy B, Lucas G, et al. 2005. Eradication of minimal residual disease in B-cell chronic lymphocytic leukemia after alemtuzumab therapy is associated with prolonged survival. J Clin Oncol, 23:2971-79.

O'Brien SM, Kantarjian HM, Thomas DA, et al. 2003. Alemtuzumab as treatment for residual disease after chemotherapy in patients with chronic lymphocytic leukemia. Cancer, 98:2657-63,

O'Brien, Keating MJ, Mocarski ES. 2006. Updated guidelines on the management of cytomegalovirus reactivation in patients with chronic lymphocytic leukemia treated with alemtuzumab. Clin Lymphoma Myeloma, 7:125-30.

Osterberg A, Fassas AS, Anagnosopoulos A, et al. 1996. Humanized CD52 monoclonal antibody Campath-1H as first line treatment in chronic lymphocytic leukemia. Br J Haematol, 93:151-3.

Osterborg A, Dyer MJ, Bunjes D, et al. 1997. Phase II multicenter study of human CD52 antibody in previously treated chronic lymphocytic leukemia. J Clin Oncol, 15:1567-74.
Rai KR, Byrd JC, Peterson B, et al. 2003. Subcutaneous alemtuzumab following fludarabine for previously untreated patients with chronic lymphocytic leukemia (CLL): CALGB study 1990. Blood, abstract 2506, 676a.

Rai KR, Byrd JC, Peterson BL, et al. 2002b. A phase II trial of fludarabine followed by alemtuzumab (Campath-1H in previously untreated chronic lymphocytic leukemia (CLL) patients with active disease. Cancer and Leukemia Group B (CALG) Study 19901. Blood, abstract 772, $205 \mathrm{a}$.

Rai KR, Freter CE, Mercier RJ, et al. 2002a. Alemtuzumab in previously treated chronic lymphocytic leukemia patients who also had received fludarabine. J Clin Oncol, 20:3891-7.

Robak T, Dmosynska A, Fetni R, et al. 2006. Incidence of genomic aberrations and associated efficacy from a phase III study alemtuzumab vs. chlorambucil as first line therapy for B-cell chronic lymphocytic leukemia (B-CLL). Blood, 108:593a (abstract 2092).

Stilgenbauer S, Cohner H. 2002. Campath-1H induced complete remission of chronic lymphocytic leukemia despite p53 gene mutation and resistance to chemotherapy. N Engl J Med, 347:452-3.

Wendtner CM, Ritgen M, Schweighoffer CD, et al. 2004. Consolidation with alemtuzumab in patients with chronic lymphocytic leukemia (CLL) in first remission experience on safety and efficacy within a randomized multicenter phase III trial of the German CLL study group (GCLLS). Leukemia, 18:1093-101. 